\title{
ANALYSIS OF PALM OIL AS OIL ADULTERANT IN OLIVE AND PUMPKIN SEED OILS IN TERNARY MIXTURE SYSTEMS USING FTIR SPECTROSCOPY AND CHEMOMETRICS
}

\author{
IRNAWATI ${ }^{1,2}$, RIYANTO S. ${ }^{1}$, MARTONO S. ${ }^{1}$, ROHMAN A.1,3*
}

${ }^{1}$ Department of Pharmaceutical Chemistry, Faculty of Pharmacy, Universitas Gadjah Mada, Yogyakarta, ${ }^{2}$ Faculty of Pharmacy, Universitas Halu Oleo Kendari, Souteast Sulawesi 93232 Indonesia, ${ }^{3}$ Institute of Halal Industry and Systems, Universitas Gadjah Mada, Yogyakarta 55281 Indonesia

Email: abdulrohmanugm@gmail.com

Received: 23 May 2019, Revised and Accepted: 25 Jul 2019

\section{ABSTRACT}

Objective: The study was designed to develop Fourier transform infrared (FTIR) spectroscopy in conjunction with chemometrics techniques of multivariate calibration and discriminant analysis (DA) for analysis of palm oil in a ternary mixture with EVOO and PSO.

Methods: FTIR spectra of pure palm oil (PO), extra virgin olive oil (EVOO), pumpkin seed oil (PSO) and its ternary mixtures randomly prepared were scanned using FTIR spectrophotometer at wavenumbers of $4000-650 \mathrm{~cm}^{-1}$ corresponding to mid-infrared region, with resolution of $8 \mathrm{~cm}-1$ and 32 scanning using sampling technique of attenuated total reflectance (ATR). Two calibrations in multivariate models, namely principle component (PCR) and partial least square (PLS) regressions were used to facilitate quantification of PO.

Results: The PLS using first derivative FTIR-ATR spectra at 3100-2750 combined with $1500-663 \mathrm{~cm}^{-1}$ showed the best prediction models for quantification of PO in ternary mixtures with EVOO and PSO. Using this condition, correlation coefficient (R) values for the relationship between actual values and FTIR predicted values of 0.9967 and 0.9906 were achieved in calibration and validation models, respectively. The errors in calibration and prediction models, expressed by RMSEC and RMSEP, were low, i.e. $0.0080 \%$ and $0.0152 \%$, respectively. DA using absorbance values at the same wavenumbers also offered the optimum discrimination model for discrimination between PO and PO mixed with EVOO and PSO in ternary mixtures.

Conclusion: This result concluded that FTIR spectra in conjunction with DA (for classification) and PLS (for quantification) is fast and accurate tools during the analysis of PO as oil adulterant in EVOO and PSO.

Keywords: Discriminant analysis, Multivariate calibration, Palm oil, Olive oil, Pumpkin seed oil

(C) 2019 The Authors. Published by Innovare Academic Sciences Pvt Ltd. This is an open-access article under the CC BY license (http://creativecommons.org/licenses/by/4.0/] DOI: http://dx.doi.org/10.22159/ijap.2019v11i5.34274

\section{INTRODUCTION}

Known as the highest olive oils, extra-virgin olive oil (EVOO) command high priced vegetable oil because EVOO is only obtained by means of the physical and mechanical processes of fresh and healthy fruits of olive (Olea europaea) in the appropriate maturation stage without any treatments which cause its original composition changed [1, 2]. As a consequence, EVOO is taken into accound as high-quality edible oil due to its nutritional benefits; the appreciated features, pleasant taste, and enjoyable flavor $[3,4]$. The evidence from epidemiological studies (especially from dietary intervention and cohort studies) trials revealed that the consumption of EVOO is associated with increased longevity [5]. Besides, EVOO is also reported in inhibiting some disease risk factors, such as diabetes, metabolic syndrome and obesity [6] and preventing certain cancers, especially breast and digestive tract cancers [7]. EVOO is rich phenolics compound which contributed to antioxidant activities and its stability [8]. In addition, pumpkin seed oil (PSO) is also considered as one of the functional edible oils [9]. PSO contained high levels of vitamin $\mathrm{E}$, carotenoids and unsaturated fatty acids, contributing to beneficial effects on human health in prevention of high cholesterol levels, prostate cancer, and molacular degeneration $[10,11]$. As a consequence, PSO may also be adulterated with cheaper seed oil like palm oil [12].

In fats and oils industry, both EVOO and PSO revealed advantageous effects to human health, desirable characteristics and limited production; therefore, they commanded expensive price which attracted to be adulterated intentionally with other edible oils [13]. Among the adulteration practices, the addition of EVOO with low price edible vegetable oils including palm oil and seed oils like soybean, corn, sunflower, pomace, and rapeseed oils is the most common fraud $[5,14]$. As a consequence, numerous methods based on chemical or molecular biology properties have been developed and used for analysis of oil adulterants in EVOO, and among the most reported ones is FTIR spectroscopy $[15,16]$.

The combination of FTIR spectroscopy with multivariate analysis or chemometrics has been used for authentication studies of EVOO from palm oil [17], corn, soybean, sunflower, rapeseed [18], corn, sunflower, soybean and hazelnut oils [19], and analysis of palm with canola oil [20] and lard in binary mixtures [21]. From literature, there are limited studies reporting the combination of FTIR spectroscopy and chemometrics employed for analysis of palm oil as adulterant in EVOO and PSO in ternary mixtures; therefore, this study was intended to analyze palm oil mixed with EVOO and PSO in ternary mixture.

\section{MATERIALS AND METHODS}

\section{Materials}

Palm oil (SunCo), pumpkin seed oil (Happy Green), canola oil (Mazola), coconut oil (Kara), corn oil (Mazola), extra virgin olive oil (Bertolli), garlic oil (Double Pagoda), ginger oil (Double Pagoda), grape seed oil (Borges), black seed oil (Al-Afiat), hazelnut oil (Fora), rice bran oil (Oryza Grace), soya bean oil (Mazola), sesame oil (Lee Kum Kee) and sunflower oil (Mazola) were obtained from local markets in Yogyakarta. The other chemicals and solvents used in this study were in the level of pro-analytical grade.

\section{Determination of fatty acids composition}

The composition of fatty acids composed PO, PSO, and EVOO was determined by gas chromatography equipped with a detector of flame ionization (GC-FID). Before being analyzed using GC-FID, the studied oils were subjected to derivatization procedure to obtain derivate methyl ester of fatty acid (FAME). The derivatization procedure and GC-FID analysis were performed according to the literature [22]. The studied oils $(50 \mu \mathrm{l})$ were added with $1.0 \mathrm{ml}$ of $n$ hexane and $0.2 \mathrm{ml}$ of $0.2 \mathrm{~N} \mathrm{NaOCH}_{3}$. The solutions were subjected to heating at $70{ }^{\circ} \mathrm{C}(10 \mathrm{~min})$. Every $2 \mathrm{~min}$, solutions were shaken vigorously, added with $1.5 \mathrm{ml}$ of $\mathrm{BF}_{3}$, and heated at $70{ }^{\circ} \mathrm{C}(10 \mathrm{~min})$. The solutions were cooled and followed by addition of $1.5 \mathrm{ml}$ of saturated $\mathrm{NaCl}$ solution. The supernatant containing FAME was injected into GC-FID (GC-FID Agilent 7890B GC (Germany). 
Separation of analytes was performed using column HP-5 (30 $\mathrm{m} \times$ $0.32 \mathrm{~mm} \times 0.25 \mu \mathrm{m}$ ). The carrier gas used was ultrapure helium with the flow rate of $2.99 \mathrm{ml} / \mathrm{min}$. The temperatures of injector and detector were set at $260{ }^{\circ} \mathrm{C}$. The injection was carried out in split manner with ratio of 15:1. The column temperature was set in gradient manner as follows: $160^{\circ} \mathrm{C}$ and hold for $2 \mathrm{~min}, 160-270{ }^{\circ} \mathrm{C}$ $\left(10^{\circ} \mathrm{C} / \mathrm{min}\right.$ rate), and finally hold for $5 \mathrm{~min}$. In addition, flow rate of the air and hydrogen ultrapure were adjusted at 400 and $40 \mathrm{ml} / \mathrm{min}$ respectively. The retention times of FAME standards (Sigma, Aldrich, USA) were used to identify FAMEs in studied oils. The percentage of fatty acid was computed as relative percentage (\%) using internal normalization technique as in [23].

\section{Preparation of calibration and validation samples}

Preparation of calibration and validation samples was adopted from Rohman et al. [28]. For making calibration samples, 20 samples consisting of PO, EVOO, and PSO in ternary mixtures at concentration ranges of $0-100.0 \% \mathrm{v} / \mathrm{v}$ were prepared randomly using random number with the aid of Excel (Microsoft Inc., USA), as shown in table 1.

For preparing validation samples, a series of different samples was preparing in the concentration ranges covered by calibration samples. All samples were analyzed using FTIR spectrophotometer.

Table 1: The composition of palm oil (PO) in ternary mixtures with extra virgin olive oil (EVOO) and pumkin seed oil (PSO)

\begin{tabular}{|c|c|c|c|}
\hline \multirow[t]{2}{*}{ No } & \multicolumn{3}{|c|}{ Concentration $(\%, v / v)$} \\
\hline & PO & EVOO & PSO \\
\hline Sample 1 & 23 & 34 & 42 \\
\hline Sample 2 & 5 & 0 & 95 \\
\hline Sample 3 & 18 & 2 & 80 \\
\hline Sample 4 & 46 & 44 & 10 \\
\hline Sample 5 & 25 & 28 & 47 \\
\hline Sample 6 & 26 & 3 & 71 \\
\hline Sample 7 & 36 & 41 & 23 \\
\hline Sample 8 & 26 & 19 & 55 \\
\hline Sample 9 & 15 & 46 & 39 \\
\hline Sample 10 & 40 & 1 & 59 \\
\hline Sample 11 & 31 & 24 & 45 \\
\hline Sample 12 & 25 & 43 & 32 \\
\hline Sample 13 & 23 & 27 & 50 \\
\hline Sample 14 & 18 & 46 & 36 \\
\hline Sample 15 & 12 & 8 & 80 \\
\hline Sample 16 & 34 & 13 & 53 \\
\hline Sample 17 & 39 & 49 & 12 \\
\hline Sample 18 & 18 & 24 & 58 \\
\hline Sample 19 & 23 & 26 & 51 \\
\hline Sample 20 & 27 & 18 & 55 \\
\hline
\end{tabular}

\section{Discriminant analysis}

Discriminant analysis (DA) for grouping samples was carried out, according to Putri et al. [29]. Discriminant analysis (DA) was used for discriminating between pure $\mathrm{PO}$ and $\mathrm{PO}$ in ternary mixture with PSO nd EVOO. For training sets, pure PO and ternary system of POPSO-EVOO were prepared in the range of $0.5-50.0 \%(\mathrm{v} / \mathrm{v})$ of $\mathrm{PO}$ was prepared. Both groups (pure PO and PO-PSO-EVOO) were classified and discriminated using DA on the basis of Cooman's plot using FTIR spectral absorbance at specific wavenumbers as variables.

\section{FTIR spectra acquisition}

The scanning of FTIR spectra of oil samples was done using FTIR spectrophotometer (Thermo Scientific Nicolet iS10, Madison, WI), equipped with the Omnic software for spectral processing. The measurements were performed in horizontal attenuated total reflectance (HATR) at wavenumbers $(1 / \lambda)$ of $4000-650 \mathrm{~cm}^{-1} \mathrm{using}$ 32 scannings with the resolution of $8 \mathrm{~cm}^{-1}$. All FTIR spectra were corrected against FTIR spectrum of air as background. After every scan, a new reference air background spectrum was taken. These spectra were recorded as absorbance values at each data point in triplicate.

\section{Chemo-metrics analysis}

Chemometrics analysis including discriminant analysis and multivariate calibrations of principle component regression (PCR) and partial least square (PLS) was performed using TQ Analyst software version 9 (Thermo Fisher Scientific, Inc.). Statistical parameters used for evaluation of multivariate calibrations performance were coefficient of determination $\left(\mathrm{R}^{2}\right)$ and root mean square error of calibration (RMSEC), as well as root, mean square error of prediction (RMSEP).

\section{RESULTS AND DISCUSSION}

Table 2 compiled fatty acid (FA) composition of studied oils in which palmitic and oleic acids are main FAs composed PO. In addition, oleic acid was present as main FA component in EVOO, while PSO is mainly composed from linoleic and oleic acids. All FAs in PO and EVOO were in agreement with those specified in Codex Allimentarius Commission, while FAs in PSO in this study was in accordance with those reported in the literature [24]. These FAs data indicated that studied oils (PO, EVOO and PSO) were not previously mixed with other oils. The difference of fatty acids determined the different intensities of functional groups of studied oils in which oils with higher levels of oleic acids would have higher intensities in peaks related to unsaturated fatty acids.

Table 2: Fatty acid composition of fatty acids in palm oil, extra virgin olive oil and pumpkin seed oil

\begin{tabular}{|c|c|c|c|c|c|c|}
\hline \multirow[t]{2}{*}{ Fatty acids } & \multicolumn{2}{|l|}{ Palm oil } & \multicolumn{2}{|c|}{ Extra virgin olive oil } & \multicolumn{2}{|c|}{ Pumpkin seed oil } \\
\hline & Exp. & Codex & Exp. & Codex & Exp. & According to literature [24] \\
\hline Palmitic acid (C16:0) & $38.45 \pm 0.17$ & $39.3-47.5$ & $11.25 \pm 0.58$ & $7.5-20$ & $11.05 \pm 0.12$ & $9.39-12.48$ \\
\hline Palmitoleic acid (C16:1) & $0.15 \pm 0.02$ & nd-0.6 & $0.68 \pm 0.02$ & $0.3-3.5$ & $0.12 \pm 0.01$ & $0.10-0.14$ \\
\hline Stearic acid (C18:0) & $6.67 \pm 0.32$ & $3.5-6.0$ & $3.12 \pm 0.09$ & $0.5-5.0$ & $4.62 \pm 0.04$ & $4.15-5.67$ \\
\hline Oleic acid (C18:1) & $40.79 \pm 0.45$ & $36.0-44.0$ & $75.12 \pm 1.05$ & $55.0-83.0$ & $30.56 \pm 1.15$ & $29.20-36.44$ \\
\hline Linoleic acid (C18:2) & $9.85 \pm 0.05$ & $9.0-12.0$ & $6.97 \pm 0.07$ & $3.5-21.0$ & $45.45 \pm 2.45$ & $42.73-55.33$ \\
\hline Linolenic acid (C18:3) & $0.31 \pm 0.01$ & nd- 0.5 & $0.29 \pm 0.02$ & $<1.5$ & $0.22 \pm 0.01$ & $0.14-0.30$ \\
\hline Arachidic acid (C20:0) & $0.20 \pm 0.01$ & nd-1.0 & $0.43 \pm 0.01$ & $<0.8$ & $0.36 \pm 0.01$ & $0.29-0.39$ \\
\hline
\end{tabular}

Exp: results obtained from the experiment in this study 
Due to its nature as fingerprint analytical technique, Fourier transforms infrared (FTIR) spectroscopy is an ideal method for analysis of complex mixtures such as edible fats and oils and other secondary metabolites extracted from specific part of plants [25]. Fig. 1 showed FTIR-ATR spectra of three edible oils, palm oil (PO), extra virgin coconut oil (EVOO), and pumpkin seed oil (PSO) scanned at mid-infrared regions corresponding to $1 / \lambda$ of $4000-650$ $\mathrm{cm}^{-1}$. Each peaks and shoulders in FTIR spectra come from the IR absorption by functional groups present in these oils. The interpretation of each peaks and shoulders in relation to functional groups in FTIR spectra was compiled in table 3. All Peaks in FTIRATR among PO, EVOO and PSO spectra are very similar. This is not surprising because the main components composing edible fats and oils were triglyceride (95-98\%), glycerol esterified with three fatty acids [27]. However, upon detailed investigation, FTIR-ATR spectra of PO, EVOO and PSO reveal slight differences in terms of band intensities (absorbance's) and the exact wavenumbers in each peak and shoulders [28].

Table 3: Functional groups responsible for absorption of peaks and shoulders in palm oil, extra virgin olive oil, and pumpkin seed oil [26]

\begin{tabular}{ll}
\hline Wavenumbers region $\left(\mathbf{c m}^{-1}\right)$ & Functional groups and vibration modes \\
\hline 3007 & cis $\mathrm{C}=\mathrm{CH}$, stretching vibration \\
2953 & methyl $\left(-\mathrm{CH}_{3}\right)$, asymmetric stretching vibration \\
2922 and 2853 & methylene $\left(-\mathrm{CH}_{2}\right)$, asymmetric and symmetric stretching vibrations \\
1744 & carbonyl $(\mathrm{C}=\mathrm{O})$, stretching vibration \\
1654 & $\mathrm{C}=\mathrm{C}$, stretching vibration \\
1460 & methylene $\left(-\mathrm{CH}_{2}\right)$, bending vibration \\
1376 & methyl $\left(-\mathrm{CH}_{3}\right)$, bending vibration \\
$1237,1160,1118,1098$ & $\mathrm{C}-\mathrm{O}$, stretching vibrations \\
996 & $-\mathrm{HC}=\mathrm{CH}-($ trans $)$, bending out of a plane \\
850 & $-\mathrm{HC}=\mathrm{CH}-($ cis $)$, bending out of plane \\
\hline
\end{tabular}

Table 4: The performance of principle component regression (PCR) and partial least square (PLS) for prediction of palm oil in ternary mixtures with extra virgin olive oil and pumpkin seed oil along with wavenumbers regions and FTIR spectral modes used (normal and derivatives)*

\begin{tabular}{|c|c|c|c|c|c|c|}
\hline \multirow[t]{2}{*}{ Multivariate calibrations } & \multirow[t]{2}{*}{ Wavenumber $\left(\mathrm{cm}^{-1}\right)$} & \multirow[t]{2}{*}{ Spectra } & \multicolumn{2}{|c|}{ Calibration } & \multicolumn{2}{|c|}{ Validation } \\
\hline & & & $\mathbf{R}$ & RMSEC & $\mathbf{R}$ & RMSEP \\
\hline \multirow[t]{18}{*}{ PCR } & \multirow[t]{3}{*}{$3100-663$} & normal & 0.9856 & 0.0166 & 0.9641 & 0.0282 \\
\hline & & derivative 1 & 0.9778 & 0.0206 & 0.9883 & 0.0230 \\
\hline & & derivative 2 & 0.9486 & 0.0311 & 0.9582 & 0.0293 \\
\hline & \multirow[t]{3}{*}{$1800-663$} & normal & 0.9855 & 0.0167 & 0.9505 & 0.0370 \\
\hline & & derivative 1 & 0.9605 & 0.0273 & 0.9683 & 0.0300 \\
\hline & & derivative 2 & 0.9040 & 0.0420 & 0.9136 & 0.0413 \\
\hline & \multirow[t]{3}{*}{$3100-2750$} & normal & 0.9836 & 0.0177 & 0.9720 & 0.0246 \\
\hline & & derivative 1 & 0.9806 & 0.0192 & 0.9760 & 0.0241 \\
\hline & & derivative 2 & 0.9620 & 0.0268 & 0.9589 & 0.0298 \\
\hline & \multirow[t]{3}{*}{$1500-663$} & normal & 0.9548 & 0.0292 & 0.9028 & 0.0433 \\
\hline & & derivative 1 & 0.9365 & 0.0344 & 0.9271 & 0.0381 \\
\hline & & derivative 2 & 0.8488 & 0.0519 & 0.8491 & 0.0525 \\
\hline & \multirow[t]{3}{*}{$3100-2750$ and $1800-663$} & normal & 0.9824 & 0.0183 & 0.9693 & 0.0270 \\
\hline & & derivative 1 & 0.9787 & 0.0202 & 0.9887 & 0.0255 \\
\hline & & derivative 2 & 0.9227 & 0.0379 & 0.9484 & 0.0321 \\
\hline & \multirow[t]{3}{*}{$3100-2750$ and $1500-663$} & normal & 0.9740 & 0.0223 & 0.9486 & 0.0316 \\
\hline & & derivative 1 & 0.9762 & 0.0213 & 0.9875 & 0.0158 \\
\hline & & derivative 2 & 0.8661 & 0.0491 & 0.8827 & 0.0465 \\
\hline \multirow[t]{18}{*}{ PLS } & \multirow{3}{*}{$3100-663$} & normal & 0.9927 & 0.0119 & 0.9713 & 0.0269 \\
\hline & & derivative 1 & 0.9959 & 0.0088 & 0.9861 & 0.0256 \\
\hline & & derivative 2 & 0.9861 & 0.0163 & 0.9811 & 0.0210 \\
\hline & \multirow[t]{3}{*}{$1800-663$} & normal & 0.9933 & 0.0114 & 0.9623 & 0.0326 \\
\hline & & derivative 1 & 0.9795 & 0.0198 & 0.9836 & 0.0262 \\
\hline & & derivative 2 & 0.9613 & 0.0271 & 0.9587 & 0.0297 \\
\hline & \multirow[t]{3}{*}{$3100-2750$} & normal & 0.9844 & 0.0173 & 0.9723 & 0.0246 \\
\hline & & derivative 1 & 0.9799 & 0.0196 & 0.9782 & 0.0230 \\
\hline & & derivative 2 & 0.9911 & 0.0130 & 0.9732 & 0.0251 \\
\hline & \multirow[t]{3}{*}{$1500-663$} & normal & 0.9718 & 0.0232 & 0.9428 & 0.0334 \\
\hline & & derivative 1 & 0.9776 & 0.0207 & 0.9762 & 0.0225 \\
\hline & & derivative 2 & 0.8450 & 0.0525 & 0.8544 & 0.0515 \\
\hline & \multirow[t]{3}{*}{$3100-2750$ and $1800-663$} & normal & 0.9935 & 0.0112 & 0.9670 & 0.0305 \\
\hline & & derivative 1 & 0.9843 & 0.0173 & 0.9868 & 0.0255 \\
\hline & & derivative 2 & 0.9978 & 0.0064 & 0.9806 & 0.0264 \\
\hline & \multirow[t]{3}{*}{$3100-2750$ and $1500-663$} & normal & 0.9962 & 0.0085 & 0.9798 & 0.0207 \\
\hline & & derivative 1 & 0.9967 & 0.0080 & 0.9906 & 0.0152 \\
\hline & & derivative 2 & 0.8338 & 0.0542 & 0.8450 & 0.0527 \\
\hline
\end{tabular}

*The selected variables were marked with bold. R = correlation coefficient; RMSEC = root mean square error of prediction; RMSEP = root mean square error of prediction. 


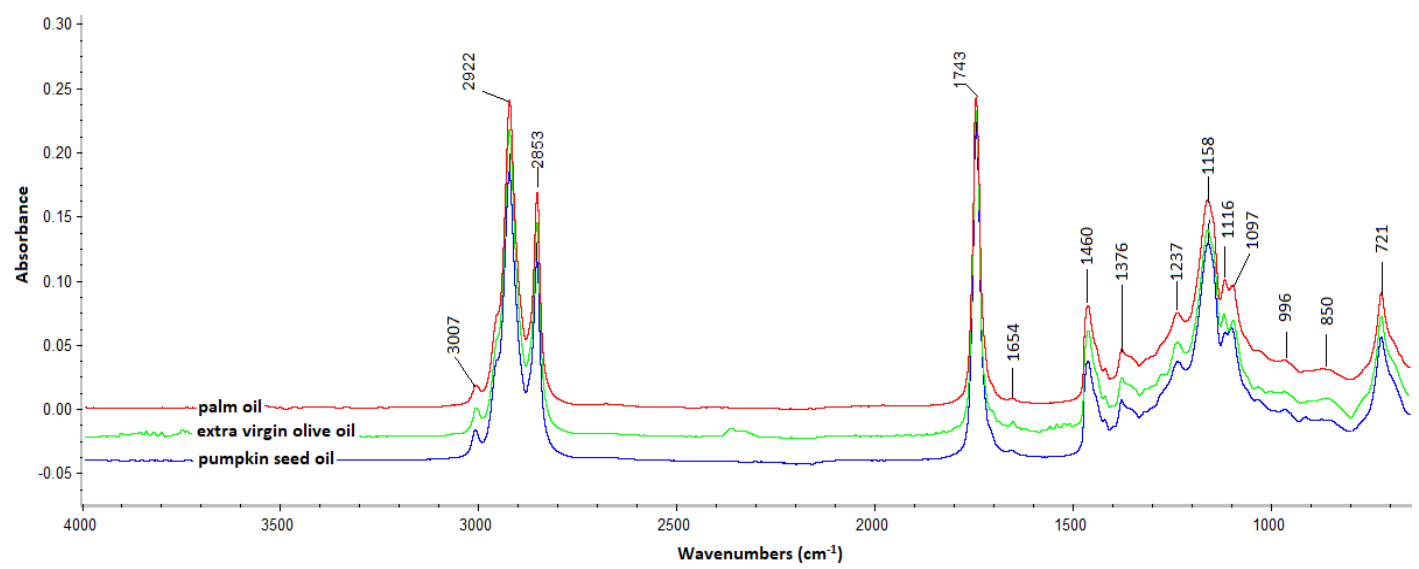

Fig. 1: FTIR spectra using attenuated total reflectance mode of palm oil, extra virgin olive oil, and pumpkin seed oil acquired at midinfrared region $\left(4000-650 \mathrm{~cm}^{-1}\right)$

Quantitative analysis of PO in ternary mixtures with EVOO and PSO was performed by the assistance of two multivariate calibrations, namely principle component regression (PCR) and partial least square (PLS). Table 4 compiled the performance of PCR and PLS for prediction of PO in ternary mixtures with EVOO and PSO along with wavenumbers regions and FTIR spectral modes used (normal and derivatives). The wavenumbers regions were selected based on the variation existed among PO, EVOO, and PSO. In addition, derivatization was intended to resolve any extensive overlapping peaks. The selection of FTIR spectroscopy conditions (multivariate calibrations, spectral modes, and wavenumbers regions) was based on the highest coefficient of correlation (R) and the lowest errors in calibration and prediction, expressed with root mean square error of calibration (RMSEC) and root mean square error of prediction (RMSEP). Finally, the first derivative FTIR spectra at the combined $1 / \lambda$ regions of 3100 2750 and $1500-663 \mathrm{~cm}^{-1}$ aided with PLS regression offered the best prediction models for quantitative analysis of $\mathrm{PO}$ in ternary mixtures with EVOO and PSO. The R values obtained for the correlation between actual values and FTIR predicted values were 0.9967 and 0.9906 in calibration and validation models, while RMSEC and RMSEP values were $0.0080 \%$ and $0.0152 \%$, respectively (fig. 2). The low errors either in calibration and prediction models were confirmed by residual analysis (fig. 2B) in which no systematic errors were observed. The high R values and lowest values of RMSEC and RMSEP indicated that FTIR spectroscopy aided with PLS offered a reliable technique for analysis of PO. This results could be extended for analysis of PO as adulterants in high valuable oils such as EVOO and PSO either in binary or ternary models.

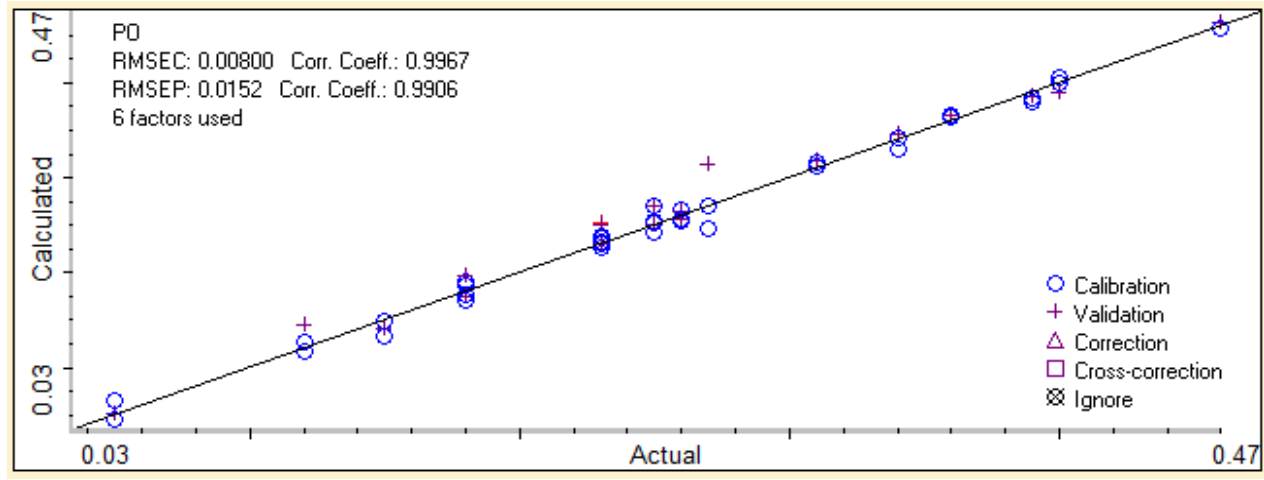

[A]

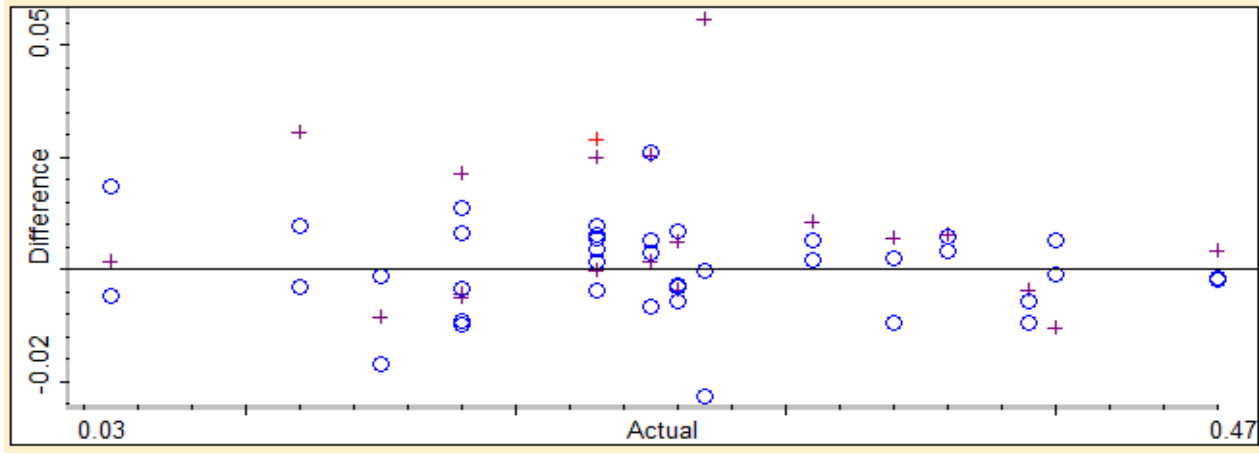

[B]

Fig. 2: The correlation between actual values ( $x$-axis) and FTIR predicted values ( $y$-axis) of palm oil in ternary mixtures with extra virgin olive oil (EVOO) and pumpkin seed oil (PSO) with a coefficient correlation of 0.9967 and 0.9906 in calibration and validation models. RMSEC = root mean square error of calibration; RMSEP = root mean square error of prediction 
Discriminant analysis (DA), one of the supervised pattern recognition techniques, was used for discrimination between pure PO and PO in ternary mixtures with EVOO and PSO. Both classes (pure and the mixture) were clearly separated, indicating that PO was different from EVOO and PSO (fig. 3), the accuracy levels of discrimination capacity were $100 \%$, meaning that no training samples were misclassified in the wrong groups. Misclassification may occur if both groups are very similar. This result could be extended that DA based on Mahalanobis distance of variables used (absorbances at wavenumbers of 3100-2750 and 1500-663 $\mathrm{cm}^{-1}$ ) was an effective means for authentication of EVOO and PSO from the possible adulteration with low-value edible oils such as palm oil.

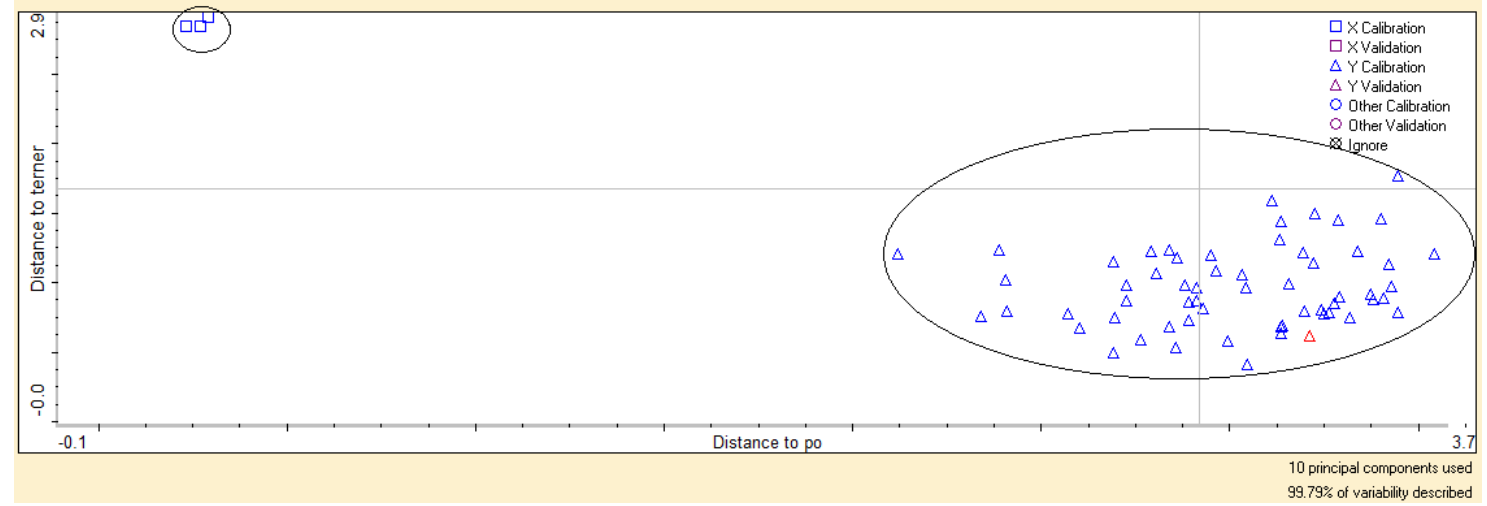

Fig. 3: The discriminant analysis expressed by Cooman's plot for the discrimination of palm oil and palm oils in ternary mixtures with extra virgin olive oil and pumpkin seed oil

\section{CONCLUSION}

Fourier transform infrared (FTIR) spectroscopy in combination with PLS and discriminant analysis could be successfully used for analysis of palm oil (PO) in ternary mixtures with extra virgin olive oil (EVOO) and pumpkin seed oil (PSO). The first derivative FTIR-ATR spectra at combined wavenumbers regions of 3100-2750 and 1500-663 $\mathrm{cm}^{-1}$ were selected for analysis of PO in ternary mixtures with EVOO and PSO with acceptable results. FTIR spectroscopy in combination with multivariate calibration of PLS and DA could be effective means to quantify and to discriminate PO mixed into EVOO and PSO.

\section{ACKNOWLEDGMENT}

The authors thank to the Ministry of Research, Technology and Higher Education, Republic Indonesia for financial support during this study through Hibah Penelitian Dasar Unggulan Perguruan Tinggi (PUPT) 2019 with contract number 2519/UN1. DITLIT/DIT-LIT/IT/2019.

\section{ABBREVIATION}

FTIR = Fourier transform infrared; ATR $=$ attenuated total reflectance; $\mathrm{PCR}=$ principle component regression; $\mathrm{PLS}=$ partial least square; RMSEC = root mean square error of calibration; RMSEP $=$ root mean square error of prediction; $\mathrm{DA}=$ Discriminant analysis; $\mathrm{PO}=$ palm oil; $\mathrm{PSO}=$ pumpkin seed oil; $\mathrm{EVOO}=$ extra virgin olive oil; $1 / \lambda=$ wavenumbers; $R=$ coefficient of correlation

\section{AUTHORS CONTRIBUTIONS}

Irnawati performed research activities and analyzed data. AR, SM and SR designed research, prepared manuscript and made critical thinking on manuscript.

\section{REFERENCES}

1. Frankel E, Bakhouche A, Lozano Sanchez J, Segura Carretero A, Fernandez Gutierrez A. Literature review on production process to obtain extra virgin olive oil-enriched in bioactive compounds. Potential use of by-products as alternative sources of polyphenols. J Agric Food Chem 2013;61:5179-88.

2. Monasterio PR, Fernandez AM, Silva FM. Olive oil by capillary electrophoresis: characterization and genuineness. J Agric Food Chem 2013;61:4477-96.

3. Hassen I, Casabianca H, Hosni K. Biological activities of the natural antioxidant oleuropein: exceeding the expectation-a mini-review. J Funct Foods 2015;18:926-40.

4. da Silveira R, Vagula JM, de Lima Figueiredo I, Claus T, Galuch $\mathrm{MB}$, Junior OOS, et al. Rapid methodology via mass spectrometry to quantify addition of soybean oil in extra virgin olive oil: a comparison with traditional methods adopted by food industry to identify fraud. Food Res Int 2017;102:43-50.

5. Buckland G, Gonzalez CA. The role of olive oil in disease prevention A focus on the recent epidemiological evidence from cohort studies and dietary intervention trials. Br J Nutr 2015;113:S94-101.

6. Perez Martinez P, Garcia Rios A, Delgado Lista J. Mediterranean diet rich in olive oil and obesity, metabolic syndrome and diabetes mellitus. Curr Pharm 2011;17:769-77.

7. Psaltopoulou T, Kosti RI, Haidopoulos D. Olive oil intake is inversely related to cancer prevalence: a systematic review and a meta-analysis of 13,800 patients and 23,340 controls in 19 observational studies. Lipids Health Dis 2011;10:127-40.

8. Gavahian M, Khaneghah AM, Lorenzo JM, Munekata PES, Garcia Mantrana I, Collado MC, et al. Review: health benefits of olive oil and its components: impacts on gut microbiota antioxidant activities, and prevention of noncommunicable diseases. Trends Food Sci Technol 2019;88:220-7.

9. Procida G, Stancher B, Cateni F, Zacchigna M. Chemical composition and functional characterization of commercial pumpkin seed oil. J Sci Food Agric 2012;93:1035-41.

10. Fruhwirth GO, Hermetter A. Production technology and characteristics of styrian pumpkin seed oil. Eur J Lipid Sci Technol 2008;110:637-44.

11. Potocnik T, Ogrinc N, Potocnik D, Kosir IJ. Fatty acid composition and $\mathrm{d} 13 \mathrm{C}$ isotopic ratio characterisation of pumpkin seed oil. J Food Compos Anal 2016;53:85-90.

12. Butinar B, Bucar Miklav M, Valenci V, Raspor P. Stereospecific analysis of triacylglycerols as a useful means to evaluate the genuineness of pumpkin seed oils: lesson from virgin olive oil analyses. J Agric Food Chem 2010;58:5227-34.

13. Aued Pimentel S, Takemoto E, Minazzi Rodrigues SR, Badolato E. Olive oil: adulteration from 1993 to 2000. Rev Inst Adolfo Lutz 2002;61:69-75.

14. Dankowska A, Małecka M. Application of synchronous fluorescence spectroscopy for determination of extra virgin olive oil adulteration. Eur J Lipid Sci Technol 2009;111:1233-9.

15. Rohman A, Che Man YB. Application of fourier transforms infrared spectroscopy for authentication of functional food oils Appl Spectrosc Rev 2012;47:1-13.

16. Rohman A. Infrared spectroscopy for quantitative analysis and oil parameters of olive oil and virgin coconut oil: a review. Int J Food Prop 2017;20:1447-56.

17. Rohman A, Che Man YB. Fourier transforms infrared (FTIR) spectroscopy for analysis of extra virgin olive oil adulterated with palm oil. Food Res Int 2010;43:886-92. 
18. Jimenez Carvelo AM, Osorio MT, Koidis A, Gonzalez Casado A, Cuadros Rodriguez L. Chemometric classification and quantification of olive oil in blends with any edible vegetable oils using FTIR-ATR and Raman spectroscopy. Food Sci Technol 2017:86:174-84.

19. Lerma Garcia MJ, Ramis Ramos G, Herrero Martinez JM, Simo Alfonso EF. Authentication of extra virgin olive oils by fouriertransform infrared spectroscopy. Food Chem 2010;118:78-83.

20. Mba O, Adewale P, Dumont MJ, Ngadi M. Application of nearinfrared spectroscopy to characterize binary blends of palm and canola oils. Ind Crops Prod 2014;61:472-8.

21. Basri KN, Hussain MN, Bakar J, Sharif Z, Abdul Khir MF Zoolfakar AS. Classification and quantification of palm oil adulteration via portable NIR spectroscopy. Spectrochim Acta A: Mol Biomol Spectrosc 2017;173:335-42.

22. Pebriana RB, Rohman A, Lukitaningsih E, Sudjadi. Development of FTIR spectroscopy in combination with chemometrics for analysis of rat meat in beef sausage employing three lipid extraction systems. Int J Food Prop 2017;20:1995-2005.

23. Rohman A, Che Man YB. Palm oil analysis in adulterated sesame oil using chromatography and FTIR spectroscopy. Eur J Lipid Sci Technol 2011;113:522-7.

24. Nederal S, Petrovic M, Vincek D, Pukec D, Skevin D, Kraljic K, et al. Variance of quality parameters and fatty acid composition in pumpkin seed oil during three crop seasons. Ind Crops Prod 2014;60:15-21.

25. Muchtaridi M, Pratiwi R, Alam G, Rohman A. Analysis of gartanin in the extract of mangosteen pericarp fruit (Garcinia mangostana L.) using spectrophotometric fourier transform infrared (FTIR) method. Rasayan J Chem 2019;12:874-9.

26. Arslan FN, Akina G, Elmas SNK, Yilmaz I, Janssen HG, Kenar A Rapid detection of authenticity and adulteration of coldpressed black cumin seed oil: a comparative study of ATR-FTIR spectroscopy and synchronous fluorescence with multivariate data analysis. Food Control 2019;98:323-32.

27. Ozulku G, Yildirim RM, Toker OS, Karasu S, Zeki Durak M. Rapid detection of adulteration of cold-pressed sesame oil adultered with hazelnut, canola, and sunflower oils using ATR-FTIR spectroscopy combined with chemometric. Food Control 2017;82:212-6.

28. Rohman A, Che Man YB, Ali ME. The authentication of virgin coconut oil from grape seed oil and soybean oil using FTIR spectroscopy and chemometrics. Int J Appl Pharm 2019;11:259-63.

29. Putri AR, Rohman A, Riyanto S. Authentication of patin (Pangasius micronemus) fish oil adulterated with palm oil using FTIR spectroscopy combined with chemometrics. Int J Appl Pharm 2019;11:195-9. 